\title{
A hidden Amazonian fauna: first record of Neoempheria bilobata Edwards, 1940 (Diptera: Mycetophilidae) in Pará State, Brazil
}

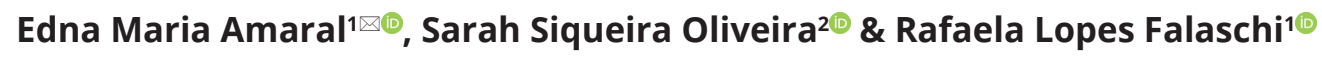

\begin{abstract}
1. Universidade Estadual de Ponta Grossa, Departamento de Biologia Estrutural, Molecular e Genética, Programa de Pós-Graduação em Biologia Evolutiva, Ponta Grossa, PR, Brazil. 2. Universidade Federal de Goiás, Campus Samambaia, Campus II. Instituto de Ciências Biológicas, Departamento de Ecologia, Goiânia, GO, Brazil.
\end{abstract}

\section{EntomoBrasilis 15: e988 (2022)}

Abstract. Neoempheria Osten Sacken is a genus of Mycetophilidae that has a life cycle associated with fungi. The genus is diverse in the Neotropical region, with 41 species known from Brazil that are predominantly known in southern and southeastern areas. This study reports on the first record of this genus for Pará state and redescribes Neoempheria bilobata Edwards, which was previously decribed from a male holotype from southern Brazil. We furnished high-resolution images and illustrations, as well as a detailed redescription of this species, based on male and female specimens.

Keywords: Bibionomorpha; Fungus gnats; Geographic distribution; Mycomyinae; Taxonomy.

\section{Edited by:}

Alberto Moreira Silva-Neto

\section{Article History:}

Received: 29.xii.2021

First Answer: 31.i.2021

Accepted: $04 . i i .2021$

Published: 03.iii.2022

$\bowtie$ Corresponding author:

Edna Maria Amaral

乃ednmaral@gmail.com

Funding agencies:

¿ Coordenação de Aperfeiçoamento de Pessoal de Nível Superior(CAPES); Conselho Nacional de Desenvolvimento Científico e Tecnológico (CNPq)

\section{EntomoBrasillis} 【pdate Check

doi: 10.12741/ebrasilis.v15.e988

(c) The Author(s) 2022. Published by Entomologistas do Brasil

This article is published by Entomologistas do Brasil and licensed under Creative Commons Licence 4.0 (CC-BY)

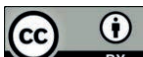

๖ Article Full Open Access
Mycetophilidae, a family of fungus gnats in the suborder Bibionomorpha (Diptera), is a diverse group of 4,500 species in 233 genera (PAPE et al. 2011; OliveIRA \& AMORIM 2014), among which 1,201 species in 55 genera are present in the Neotropics (OliveIRA \& Amorim 2014; AmAral et al. 2022). These insects are generally found in damp habitats that favor wood-growing fungi, with larvae typically feeding on fungal fruiting bodies, while the adult diet is poorly understood (OlIVEIRA et al. 2015).

Mycetophilids comprise six subfamilies (OLIVEIRA \& AMORIM 2021), including Mycomyinae which contains the genus Neoempheria Osten Sacken, 1878. Of the 153 Neoempheria species described worldwide (Fungus GnATs OnLINE 2021), 69 occur in the Neotropics and 41 occur in Brazil; however, there is no record of these fungus gnats in the Amazon Biome (OLIVEIRA \& AMORIM 2014). Based on the morphology of male terminalia, Neotropical Neoempheria species are divided into eigh groups named A, B, C, D, E, F, G, and H (EDWARDS 1940).

Neoempheria bilobata was described by Edwards, in 1940, as belonging to the species group C, characterized by, for instance, the "wings highly adorned" (EDWARDS 1940) and "pleurae with oblique dark stripe, extending from base wing across anepisternite to base of fore coxa" (EDWARDS 1940). The original descriptions is based on eight males and two females specimens including the holotype housed at the Natural History Museum, in London.

In this study, we report on the first record of $N$. bilobata from the Amazonian biome, in Pará state, Brazil, collected approximately 50 years after the species was first observed in Santa Catarina state by Fritz Plaumann. Specimens were collected from an unidentified mushroom, and a detailed redescription with illustrations, photos, and species distribution map were generated.

\section{MATERIAL AND METHODS}

The specimens were collected from the field research area of the Museu Paraense Emílio Goeldi (MPEG), Belém municipality, Pará state, Brazil. The collected fungus was transferred to the MPEG laboratory for rearing until adult emergence, but the larval stages were not monitored. Two adults $N$. bilobata emerged, a male and a female, that were pinned and will be housed in the MPEG entomological collection.

The adult's terminalia and wings were dissected. The terminalia was dehydrated in $80 \%$ alcohol for $10 \mathrm{~min}$, cleared in a solution of $\mathrm{KOH}$ on a hot plate at $40^{\circ} \mathrm{C}$ for $20-40 \mathrm{~min}$, neutralized in $10 \%$ acetic acid, then preserved in glycerine. The wing was subjected to the same dehydration process before being mounted on a permanent slide impregnated with Canada Balsam.

Photos of the wing were taken with a digital camera (MC170 HD, Leica, Wetzlar, Germany) connected to a stereomicroscope (M205 C, Leica) using LAS 4.8.0 software (Leica Application Suite). The slide-mounted material was photographed using an epifluorescence 
microscope (BX41, Olympus, Tokyo, Japan) with a digital camera (CCD DP71, Olympus) using DP controller software (Olympus) to capture images. Illustrations were vectorized using Adobe Illustrator CC 2015. Adult specimens were identified by comparing their morphological characters with those described in the literature, following the terminology defined by Søu (2017) and AmARAL et al. (2022). The map of the species' geographic distribution was prepared using ArcGIS 10.1 (ESRI 2012).

\section{Acronyms used in this work}

NHM - Natural History Museum, London, United Kingdom.

MPEG - Museu Paraense Emílio Goeldi, Belém, Brazil.

\section{RESULTS}

\section{Genus Neoempheria Osten Sacken, 1878}

Neoempheria bilobata Edwards, 1940: 113, Figure 3b (M terminalia), pl. 1, Figure 11 (wing). Type-locality: Brazil, Santa Catarina, Seara, Nova Teutônia. Distr.: Brazil (Santa Catarina). Ref.: Amorim \& OliveIRA 2013: 63 (comments on types and label data), Figure 173 (habitus). Holotype male, NHM.

\section{Redescription}

Material examined. 1 Male, Belém, PA, Brazil, Campus de Pesquisa do Museu Paraense Emílio Goeldi, Mata secundária [Field research area of the MPEG, secondary forest], 24.IV.2019, criado em cogumelo [reared in mushroom], F. S. Carvalho-Filho [MPEG]; 1 Female, same data as male specimen [MPEG].

Male (Figures 2, 3A, 4-6):
Head (Figures 2A-B): Vertex brownish, with scattered setae, yellowish around eyes. Two ocelli centralized in the head with a black occiput. Frons light brown. Face and clypeus yellowish, covered with setulae. Labellum yellowish, ventrally darker; maxillary palpus brownish, apical segment lighter, segments 3-5 of similar length, first two segments short. Antenna shorter than thorax, scape and pedicel yellow, rounded, with apical setae dorsally. Flagellomeres slightly longer than wide, flagellomeres 1-2 yellow, 3-14 light brown.

Thorax (Figures 2A-B): Yellow, with an oblique dark stripe, extending from the base wing across proepimeron, to the base of the front coxa. Pronotum yellow, with strong, long, black bristles. Proepimeron brownish posteriorly, bare. Anepisternum yellow, with a large transverse brown macula on posterior two-thirds, bare. Katepisternum yellow, with a large transverse brown macula across the two basal thirds, bare. Mesepimeron yellow, posterior margin brownish, bare. Laterotergite yellow, except for a brownish straight band following the anterodorsal margin, bare. Mediotergite yellow ventrally, a brownish triangular mark dorsally, bare. Mesoand metapleura yellow, entirely bare. Scutum yellow, with five brown stripes fusing posteriorly, covered with short and long setae, a pair of stronger dorsocentral and a pair of stronger dorsolateral setae posteriorly. Scutellum yellow, with a pair of long scutellar bristles and a few scattered setulae. Legs yellow, except for a brownish macula along the length of the hind femur, covering the surface laterally; forecoxa with some brownish maculae anteriorly, with strong setae in a line along posterior and ventral margins; hind femur compressed laterally; tibial setae regularly aligned; tibial spur I almost twice the length of tibial diameter at apex, tibial spurs II and III almost four times the length of tibial diameter at the apex. Halter stem whitish, knob black, setose.

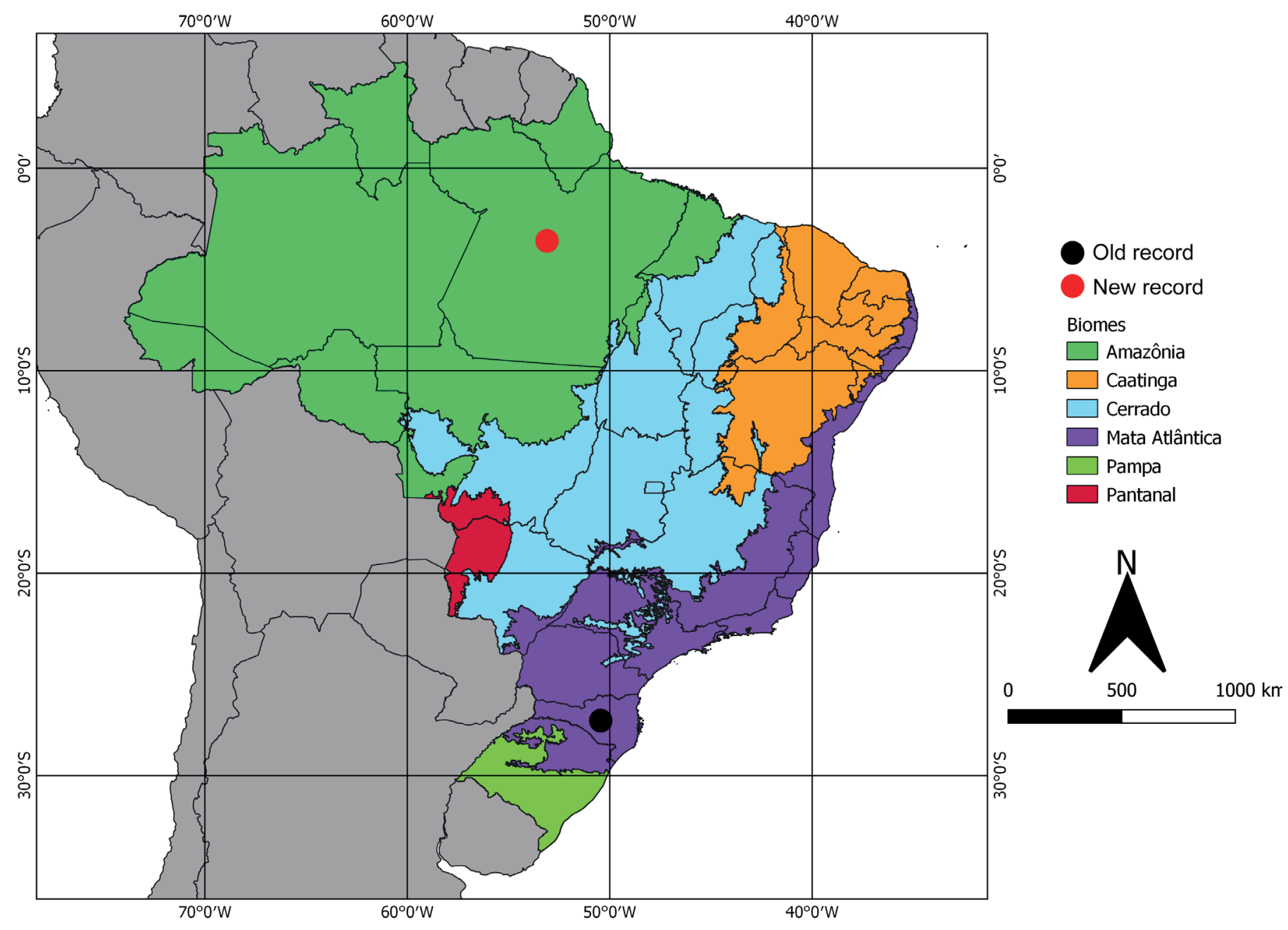

Figure 1. Map of the Brazilian biomes. 
Wing (Figure $3 \mathrm{~A}$ ): Wing venation and color pattern as in Figure 3A.

Abdomen (Figures 2A-B): Tergites 1-6 yellow, with a trapezoid brown macula medially and a yellow median straight line; tergite 7 yellow. Sternites 1, 2, and 7 yellow; sternites 3-5 with brown areas on its surface.

Terminalia (Figures 4-6): Yellow, with a brown gonocoxite. T9 weakly developed and sclerotized, bilobed at apex, with a few setae distally. Gonocoxite with two main projections, a large dorsal and brown projection extending beyond apex of gonostylus, bifid apically, densely covered with setae on the external face, apex bifurcation bare, beside an inner projection, finger-like, half the length of the external projection, covered with setulae. Gonostylus yellow, well developed, with two main elongated projections, external part of one more densely setose, and an inner branch, bare, curved medially, with a spun-like with four spines on inner margin. Gonocoxal apodeme short, sclerotized; parameres strongly developed, membranous, bare; cercus and S10 rounded, with some small setae distally, well developed.

Female (Figures 3B, 7-10). Similar to male, except as follows: basisterno brownish, hind coxa with brownish maculae; abdominal tergite 1 brown, with an anterior straight yellow band, tergites 2-5 brown, with a posterior straight brown

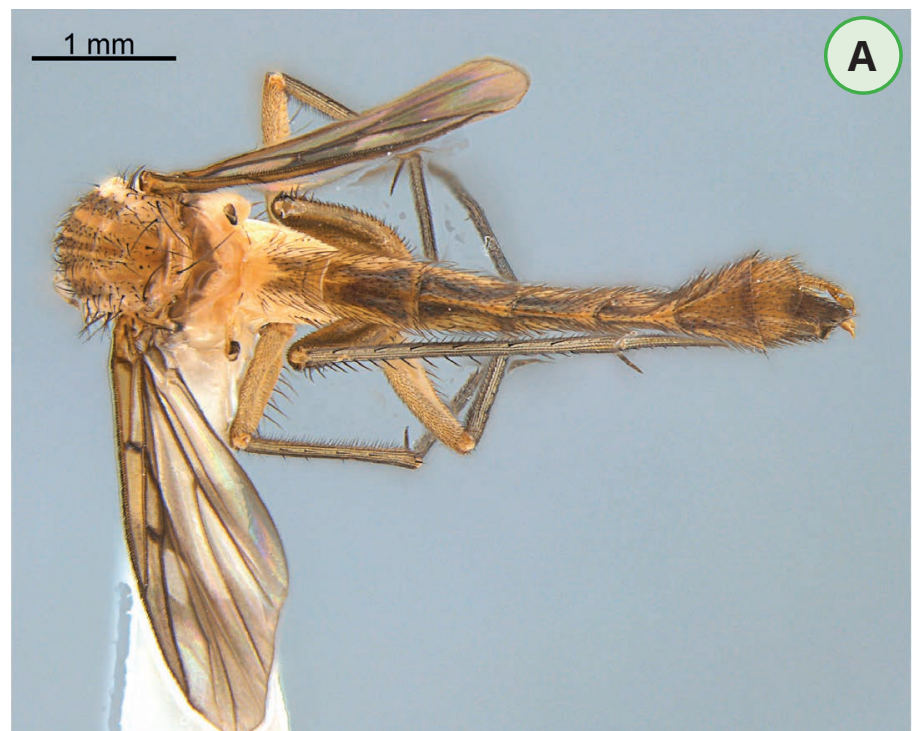

band, tergite 6 brown, with posterior corners brown, tergite 7 brown. Sternites 1-2, 6-7 yellow, sternites 3-5 brown with posterior corners yellow. Wing venation and color pattern as in Figure 3B. Terminalia (Figures 8-10): Yellow. Sternite 8 covered with setae, inner margin slightly concave; tergite 8 covered with microtrichia, bare of setae; genital fork well developed, reaching segment 7 anteriorly; cercus short, twosegmented, apical cercus (cerc 2 or cercus two) rounded, approximately a quarter of the length of the basal cercus (cerc 1, basicercus, or cercus one).

Distribution: Brazil (Pará, Santa Catarina) (Figure 1).

\section{DISCUSSION}

According to EDWARDS (1940), N. bilobata is positioned in Group C of Neotropical Neoempheria because its thoracic pleura has an oblique dark stripe that extends from the base of the wing and across the anepisternum to the base of the front coxa, and a haltere with a dark knob. Both features were visualized (Figures 2B,7B) and subsequently used to identify the specimens in this study.

A distinctive characteristic that differentiates N. bilobata from similar species in Group C (Neoempheria spinosa Edwards, 1940; Neoempheria brevicauda Edwards, 1940; Neoempheria simplex Edwards, 1940 and Neoempheria borgmeieri Edwards, 1940 ) is the dark streak that runs almost the whole length

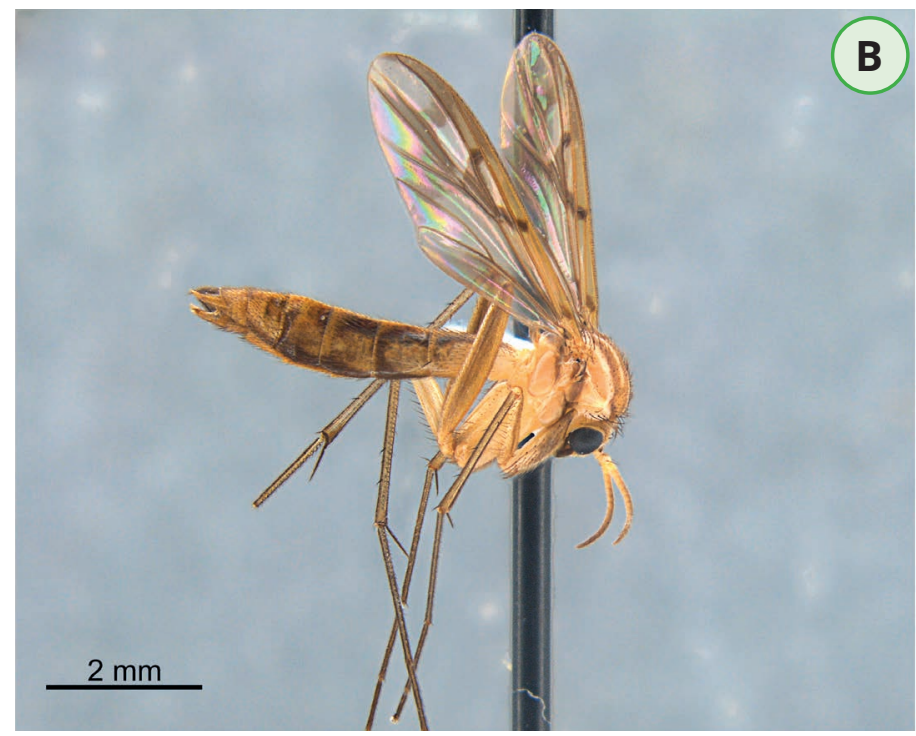

Figure 2. Neoempheria bilobata, male (Belém, Pará). A. Habitus, dorsal view. B. Habitus, lateral view.
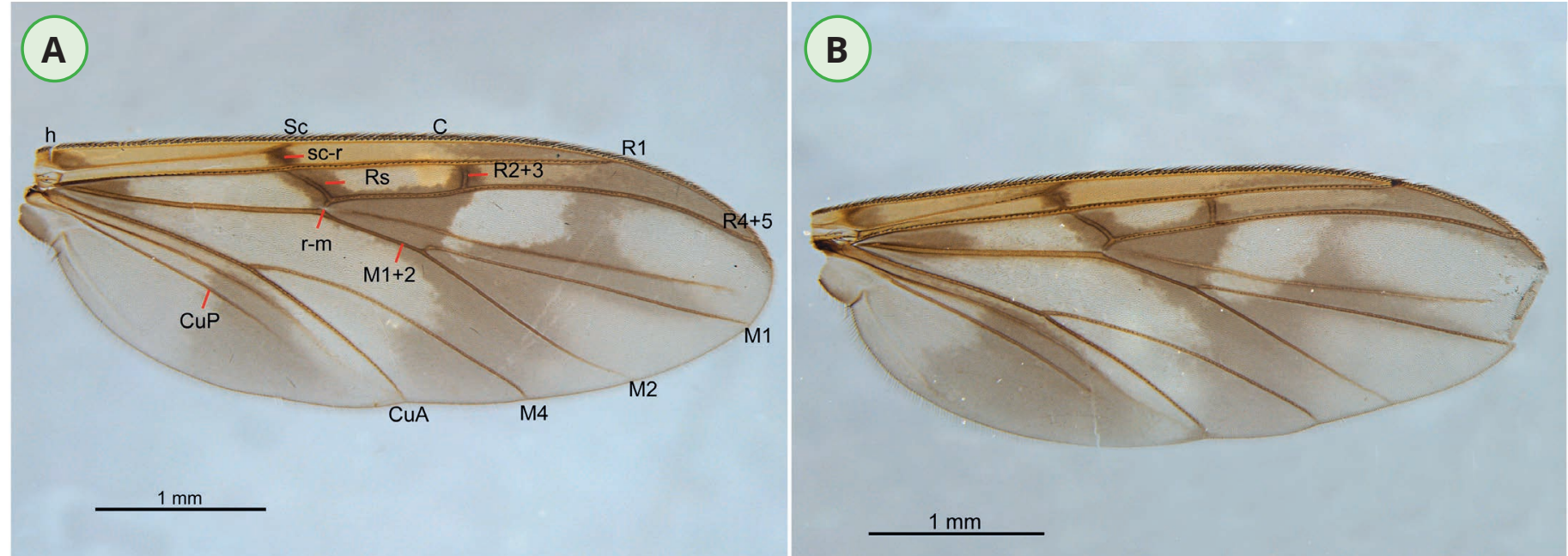

Figure 3. Neoempheria bilobata (Belém, Pará). A. Male wing. B. Female wing. Abbreviations: $C$, costal vein; CuA, anterior branch of cubital vein; cup, posterior branch of cubital vein; $h$, humeral crossvein; $M_{1}$, first branch of media; $M_{2}$, second branch of media; $M_{4}$, fourth branch of media; $M_{1+2}$, medial vein; $R_{1}$, anterior branch of radius; $R_{2+3}$, second branch of radius; $R_{4+5}$, third branch of radius; $r-m$, radial-medial crossvein; $R s$, radial sector; $S c$, subcostal vein; sc-r, subcostal-radial crossvein. 
of its hind coxa (EDWARDs 1940). This was one of the external morphological features that we observed during the identification process (Figures 2B, 7B), and it is also visible in the holotype image in AmOrim \& OLIVEIRA (2013, Figure 173).

The original description of $N$. bilobata highlights the presence of "about three stout bristles on inner lobe" (EDWARDS 1940). We verified that there were four small spines on the inner margin of one of the gonostylus projections (Figures 4A,
$4 B, 5 B)$. Further, the morphology of tergite 9 was equal to that described by EDwARDs (1940, Figure 3b) being weakly developed and sclerotized, bilobed at the apex, and covered with a few distal setae.

The presence of $N$. bilobata in Pará state was unexpected due to the continental dimensions of Brazil and the variety of habitats within its different biomes. However, two factors should be taken into consideration in a discussion about $N$.
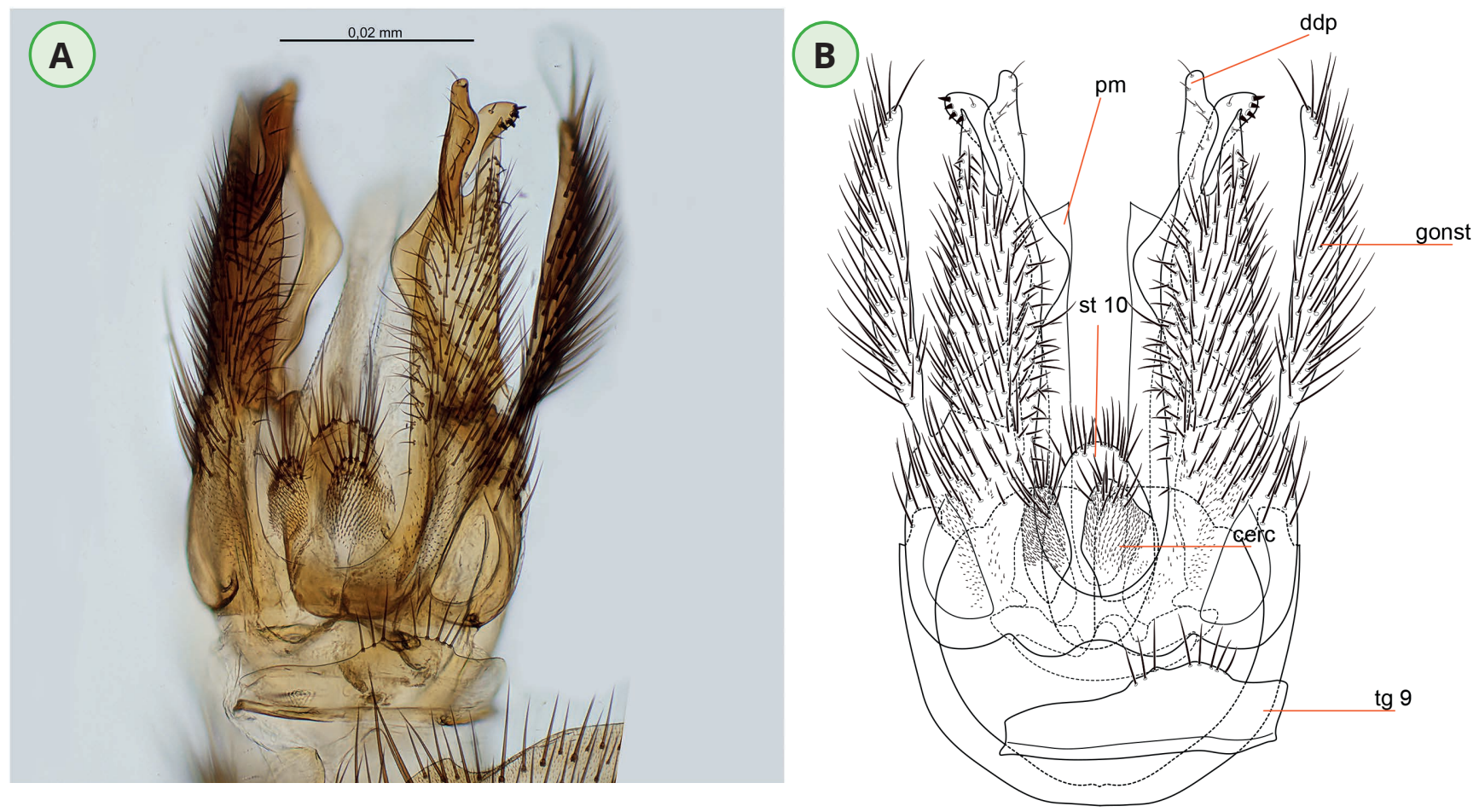

Figure 4. Neoempheria bilobata, male (Belém, Pará). A. Dorsal view of the male terminalia. B. Illustration of the dorsal view of the male terminalia. Abbreviations: cerc, cercus; $d d p$, dorsal distal projection; gonst, gonostylus; pm, paramere; st, sternite; tg, tergite.
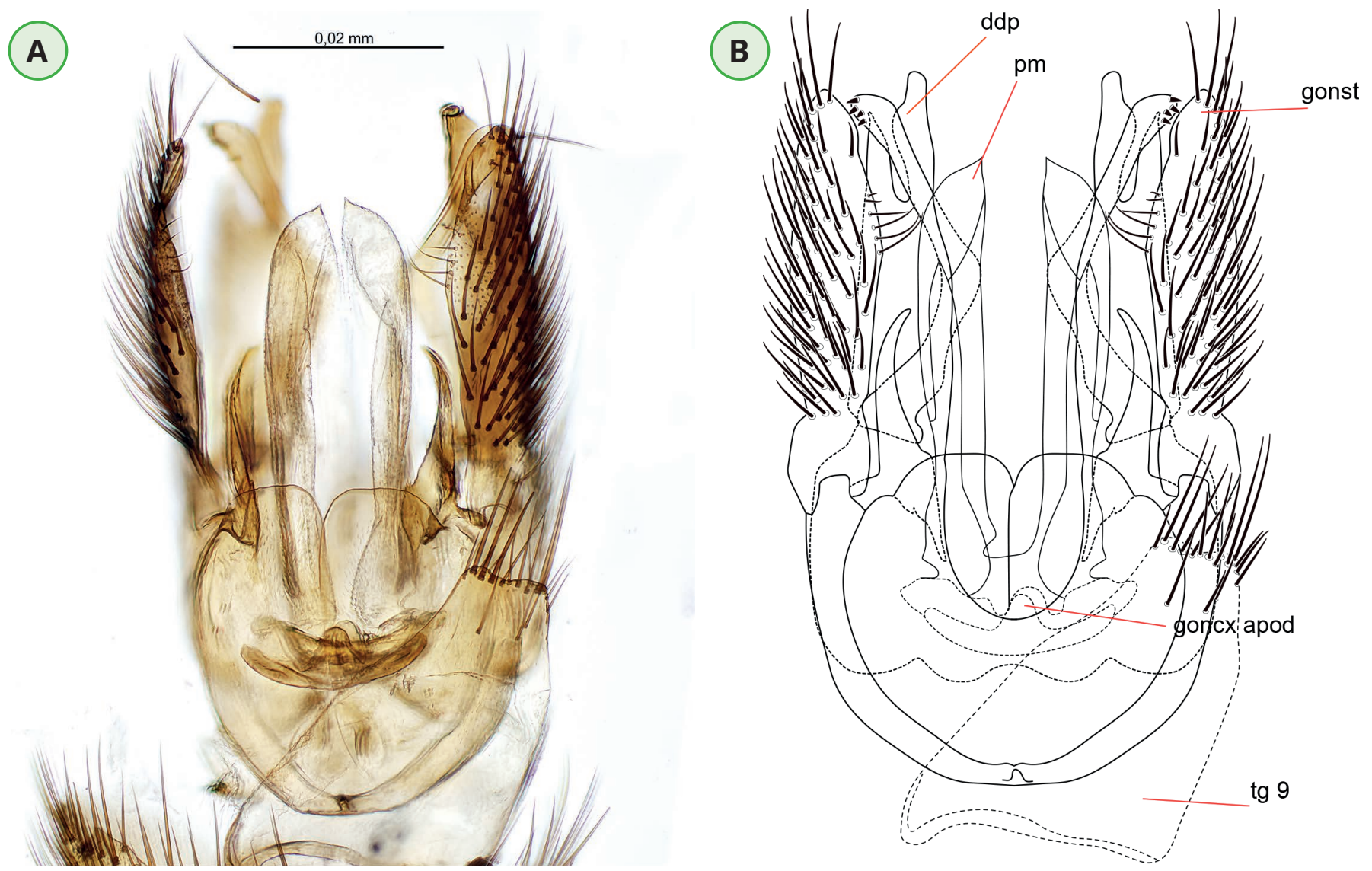

Figure 5. Neoempheria bilobata, male (Belém, Pará). A. Ventral view of the male terminalia. B. Illustration of the ventral view of the male terminalia. Abbreviations: $d d p$, dorsal distal projection; goncx apod, gonocoxal apodeme; gonst, gonostylus; $p m$, paramere; tg, tergite. 

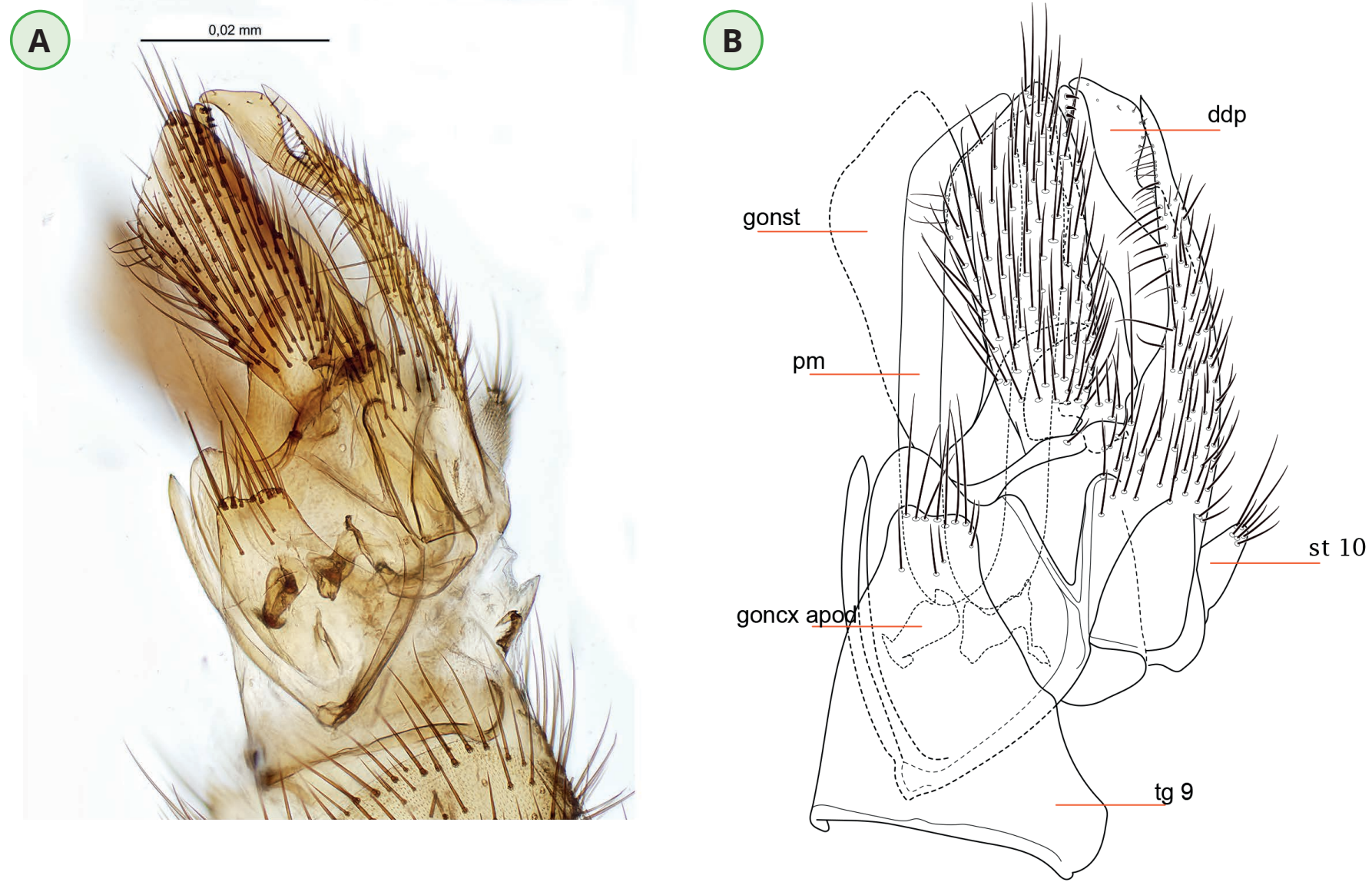

Figure 6. Neoempheria bilobata, male (Belém, Pará). A. Lateral view of the male terminalia. B. Illustration of the lateral view of the male terminalia. Abbreviations: ddp, dorsal distal projection; goncx apod, gonocoxal apodeme; gonst, gonostylus; pm, paramere; st, sternite; tg, tergite.
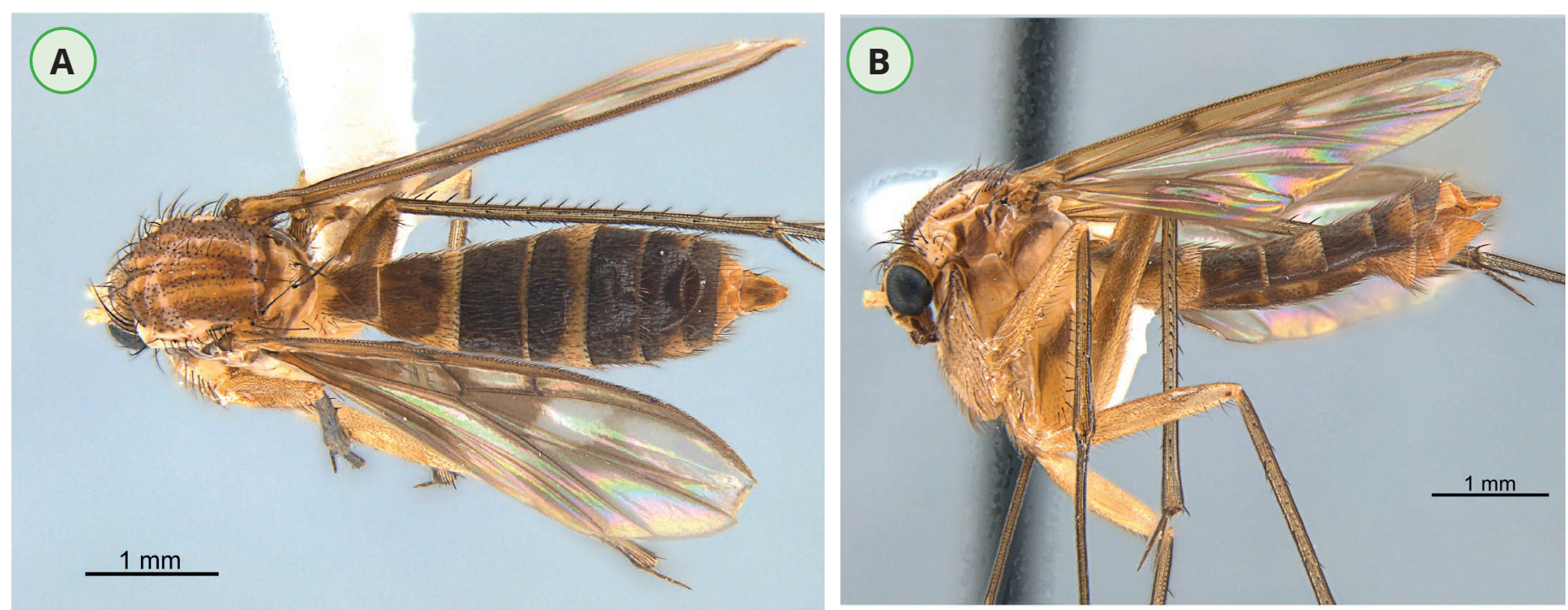

Figure 7. Neoempheria bilobata, female (Belém, Pará). A. Habitus, dorsal view. B. Habitus, lateral view.

bilobata distribution. First, a recent study of Neoempheria suggests it contains generalist species that are associated with a variety of fungal hosts (see Oliveira et al. 2015). It is possible that the genus contains carnivorous larva "that lives in slimy webs on decaying wood or on soil litter but not necessarily on the surface of fungal fruiting bodies" (JAKOVLEV 2012). Thus, Neoempheria may be more adaptable to different environments than previously thought. Second, previously known species of the genus widely distributed in Neotropical region as, for instance, Neoempheria bipectinata Edwards, 1940; Neoempheria lanei Edwards, 1940; Neoempheria larifuga Coher, 1959; Neoempheria ornatipennis (Enderlein, 1910), Neoempheria plaumanni Edwards, 1940 (OLIVEIRA \& AMORIM 2014; Oliveira et al. 2015), a kind of distribution recently documented for Manota Williston in Neotropics as well (KURINA et al. 2018).

\section{ACKNOWLEDGEMENTS}

We are thankful to Fernando da Silva Carvalho-Filho (MPEG) for the access to material of $N$. bilobata. To the editor and anonymous referees for their careful reading of the manuscript and helpful suggestions. Along the preparation of this paper, EMA and RLF were benefited from the Coordenação de Aperfeiçoamento de Pessoal de Nível Superior - Brasil (CAPES - Finance Code 001), SSO from Conselho Nacional de Desenvolvimento Científico e Tecnológico (CNPq) (428471/2016-1). 

A $1.0 \mathrm{~mm}$

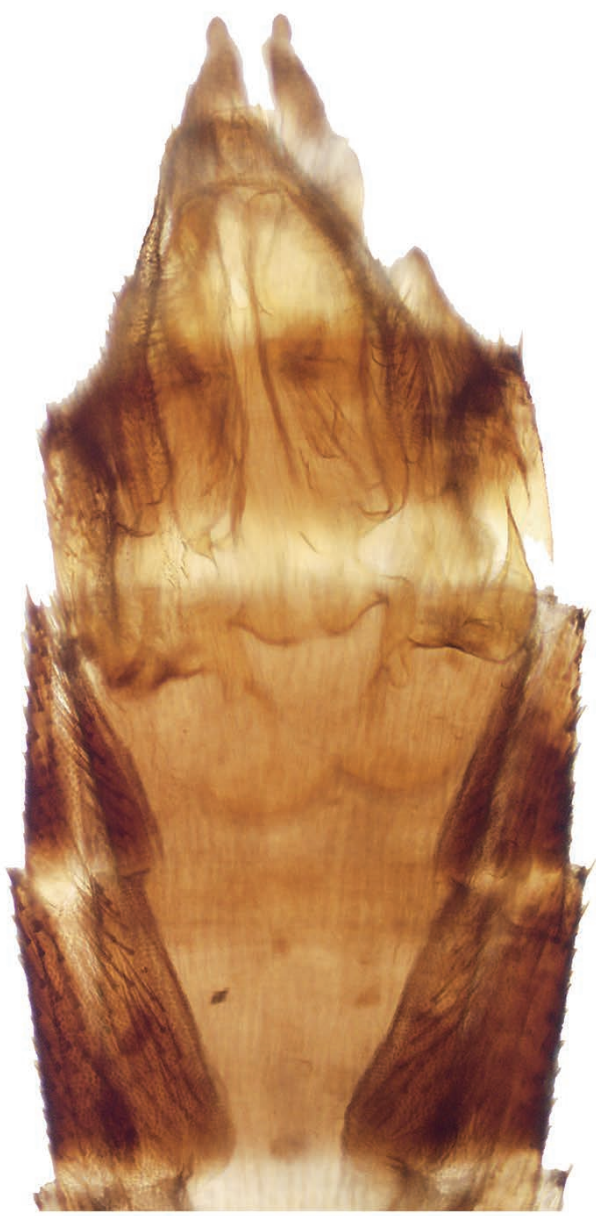

(B)

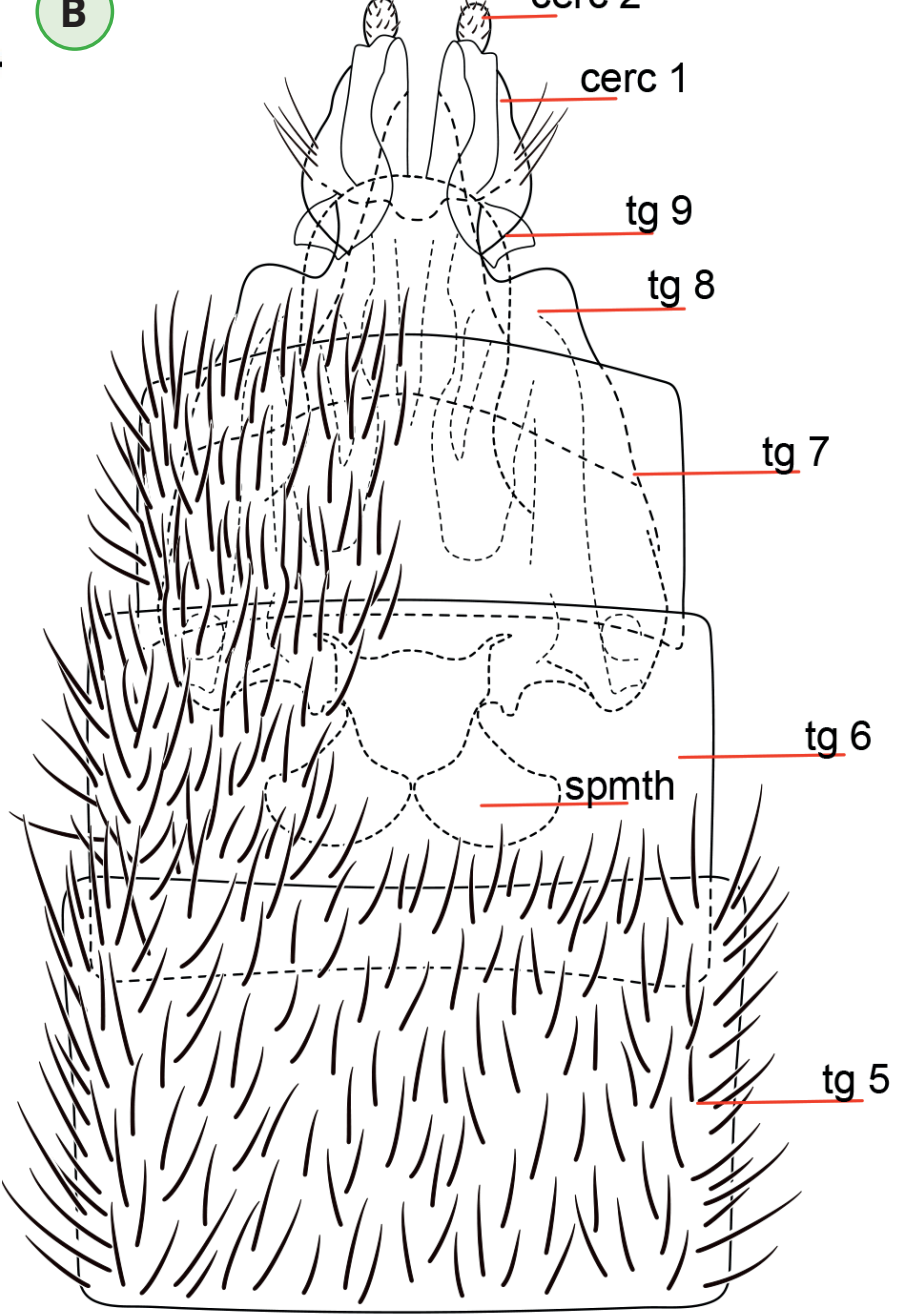

Figure 8. Neoempheria bilobata, female (Belém, Pará). A. Dorsal view of the female terminalia. B. Illustration of the dorsal view of the female terminalia. Abbreviations: cerc 1, cercus one of female terminalia; cerc 2, cercus two of female terminalia; spmth, spermatheca; tg, tergite.

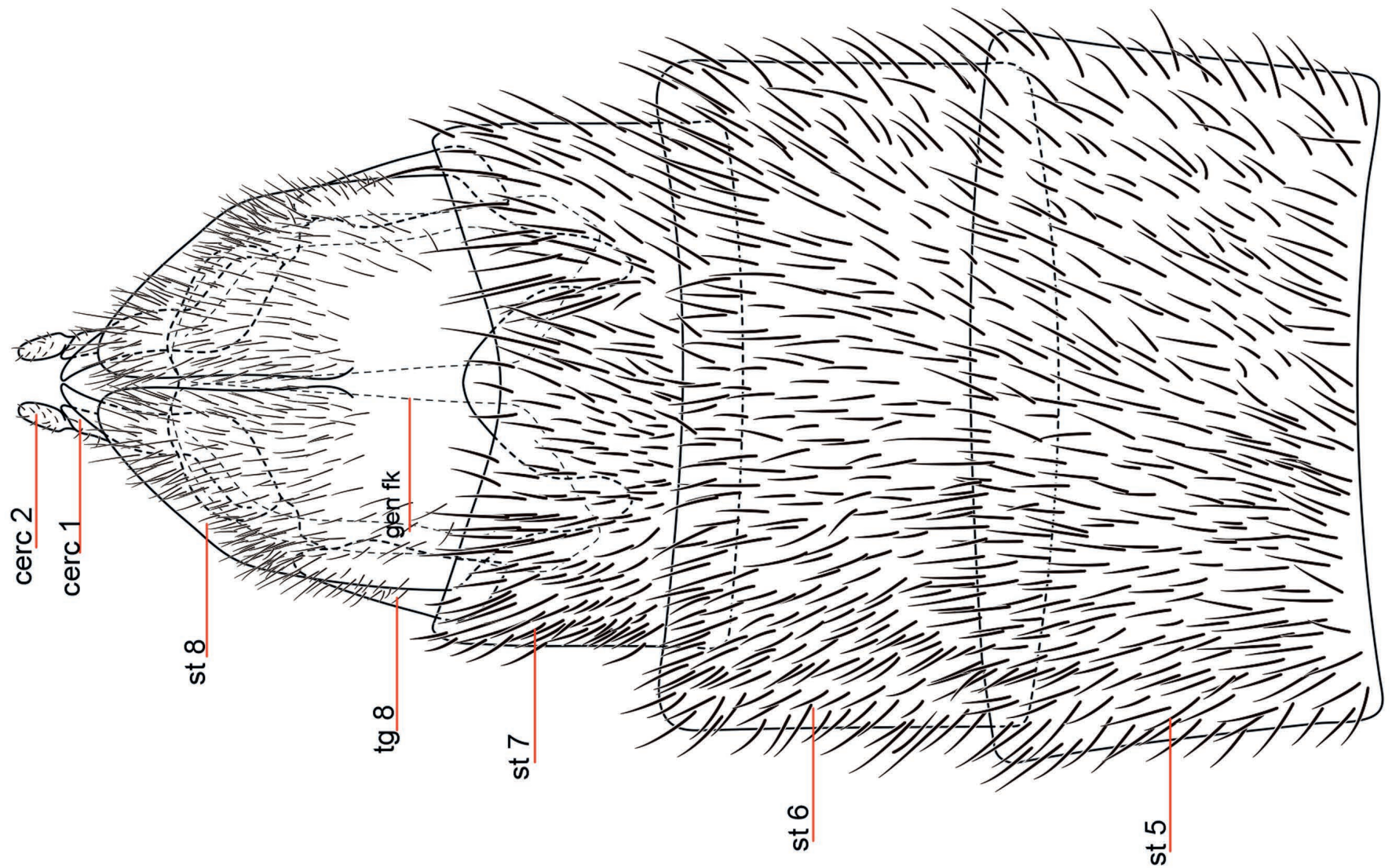

Figure 9. Neoempheria bilobata, female (Belém, Pará). Illustration of the ventral view of the female terminalia. Abbreviations: cerc 1, cercus one of female terminalia; cerc 2, cercus two of female terminalia; gen fk, genital fork; st, sternite; tg, tergite. 


\section{$1.0 \mathrm{~mm}$}

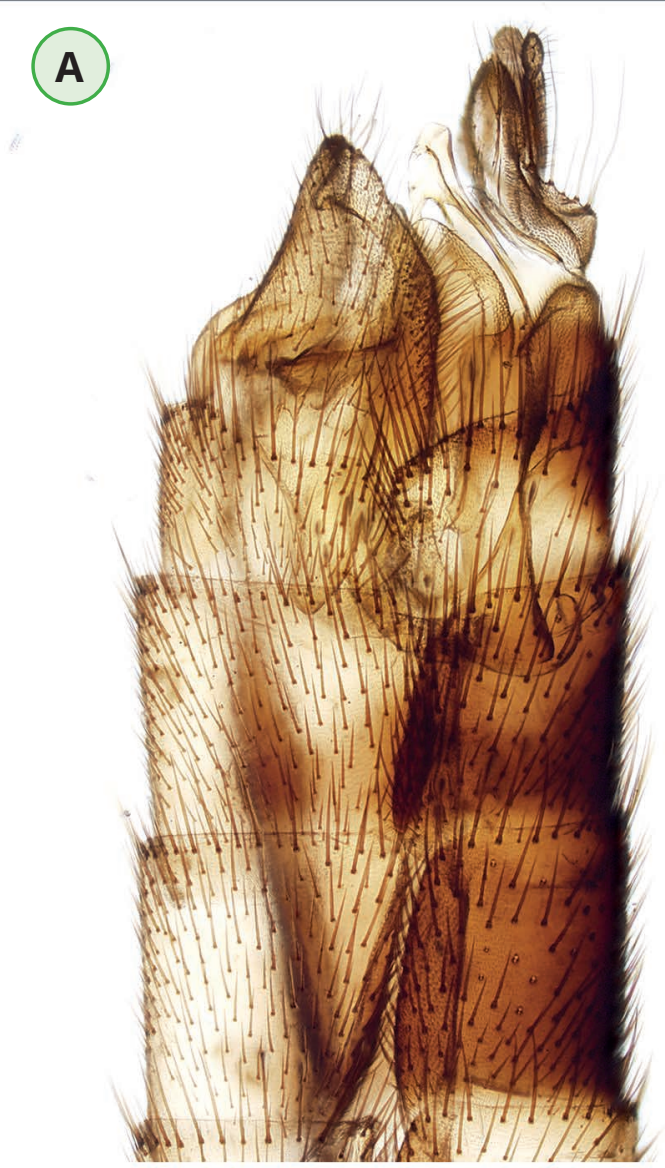

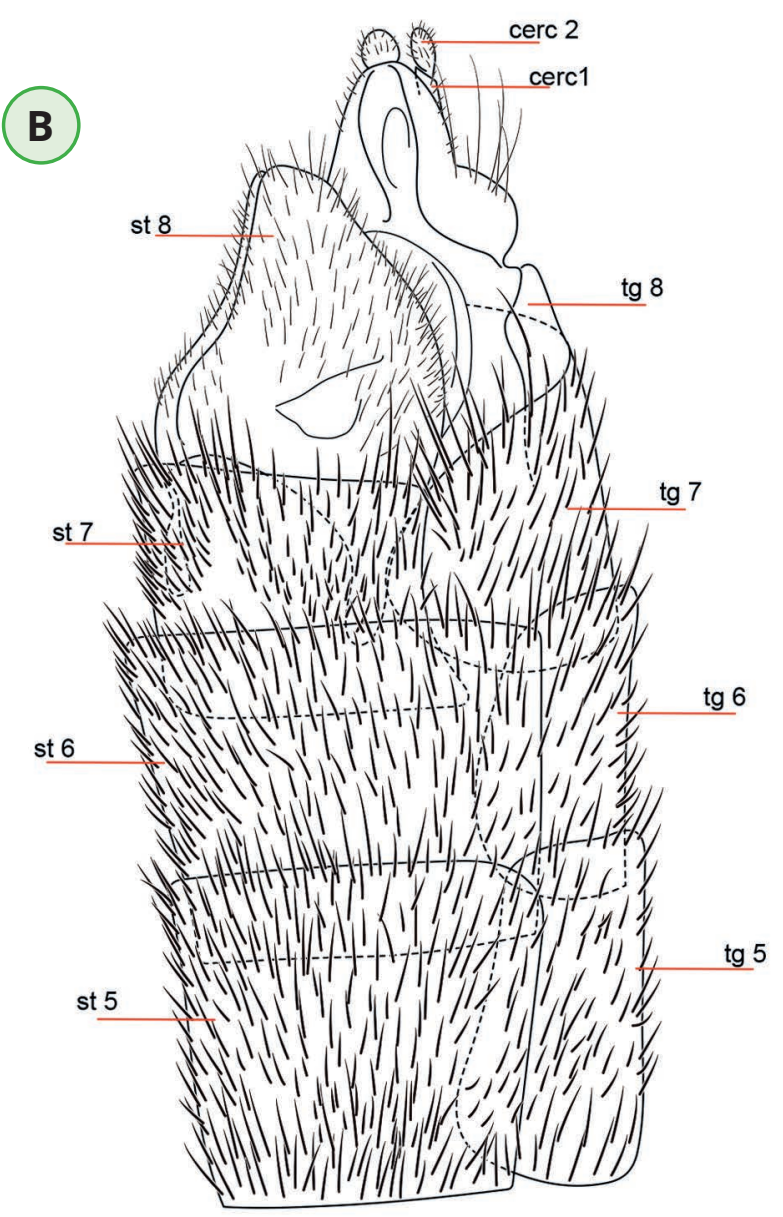

Figure 10. Neoempheria bilobata, female (Belém, Pará). A. Lateral view of the female terminalia. B. Illustration of the lateral view of the female terminalia. Abbreviations: cerc 1, cercus one of female terminalia; cerc 2, cercus two of female terminalia; st, sternite; tg, tergite.

\section{REFERENCES}

Amaral, EA, SS Oliveira \& RL Falaschi, 2022. An unknown world in the Neotropical region: a complete life cycle of a new species of Monoclona Mik, 1886 (Diptera: Mycetophilidae: Sciophilinae). Zootaxa, 5091: 107-130. DOI: https://doi.org/10.11646/zootaxa.5091.1.4

Amorim, DS \& SS Oliveira, 2013. Types of Neotropical Mycetophilidae. (Diptera) at the Natural History Museum collection, London. Zootaxa, 3726: 1-119. DOI: https://doi.org/10.11646/zootaxa.3726.1.1

Edwards, FW, 1940. Neotropical Neoempheria (Diptera, Mycetophilidae). Novitates Zoologicae, 42: 107-129.

ESRI - Environmental Systems Research Institute, 2012. ArcGIS Release 10.1. Redlands, CA.

Fungus Gnats Online, 2021. Classification of Neoempheria. Available in: <https://sciaroidea.myspecies.info/ taxonomy/45437>. [Access: 23.xii.2021].

Jakovlev, J, 2012. Fungal hosts of mycetophilids (Diptera: Sciaroidea excluding Sciaridae): a review. Mycology, 3: 1123. DOI: https://doi.org/10.1080/21501203.2012.662533

Kurina, O, H Hippa \& DS Amorim, 2018. A contribution to the systematics of the genus Manota Williston (Diptera: Mycetophilidae) in Brazil. Zootaxa, 4472: 1-59. DOI: https://doi.org/10.11646/zootaxa.4472.1.1

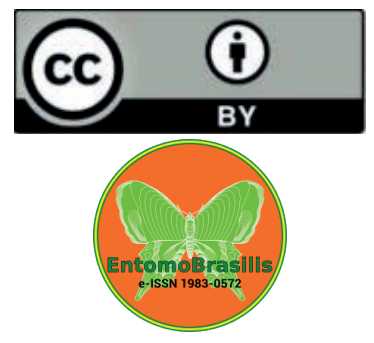

Oliveira, SS \& DS Amorim, 2014. Catalogue of Neotropical Diptera. Mycetophilidae. Neotropical Diptera, 25: 1-87.

Oliveira, SS \& DS Amorim, 2021. Phylogeny, Classification, Mesozoic fossils, and Biogeography of the Leiinae (Diptera: Mycetophilidae). Bulletin of the American Museum of Natural History, 446: 1-108. DOI: https://doi.org/10.1206/0003-0090.446.1.1

Oliveira, SS, FF Albertoni, CJ Borkent \& DS Amorim, 2015. First record of Neoempheria Osten Sacken (Diptera, Mycetophilidae) biology in the Neotropical region, with associations between its larvae and fungi. Biodiversity data journal, 3: e5073. DOI: https://doi.org/10.3897/ BDJ.3.e5073

Osten-Sacken, CR, 1878. Catalogue of the described Diptera of North America (2nd Edition). Smithsonian Miscellaneous Collections, 16: 1-276.

Pape, T, V Blagoderov \& MB Mostovski, 2011. Order Diptera Linnaeus, 1758. In: Zhang, Z-Q. (Ed.), Animal biodiversity: An outline of higher-level classification and survey of taxonomic richness. Zootaxa, 3148: 222-229. DOI: https://doi.org/10.11646/zootaxa.3148.1.42

Søli, GEE, 2017. Mycetophilidae (Fungus Gnats), pp. 533-555. In: Kirk-Spriggs, AH \& BJ Sinclair (Eds.). Manual of Afrotropical Diptera. Vol. 2. Nematocera \& Lower Brachycera. SANBI Publishing, Pretoria.

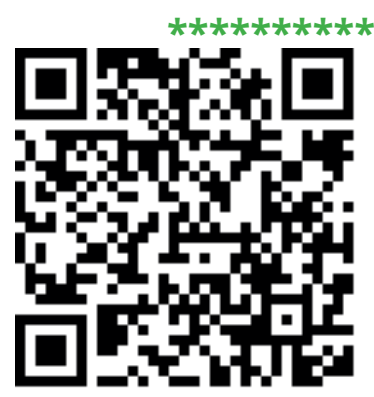

